
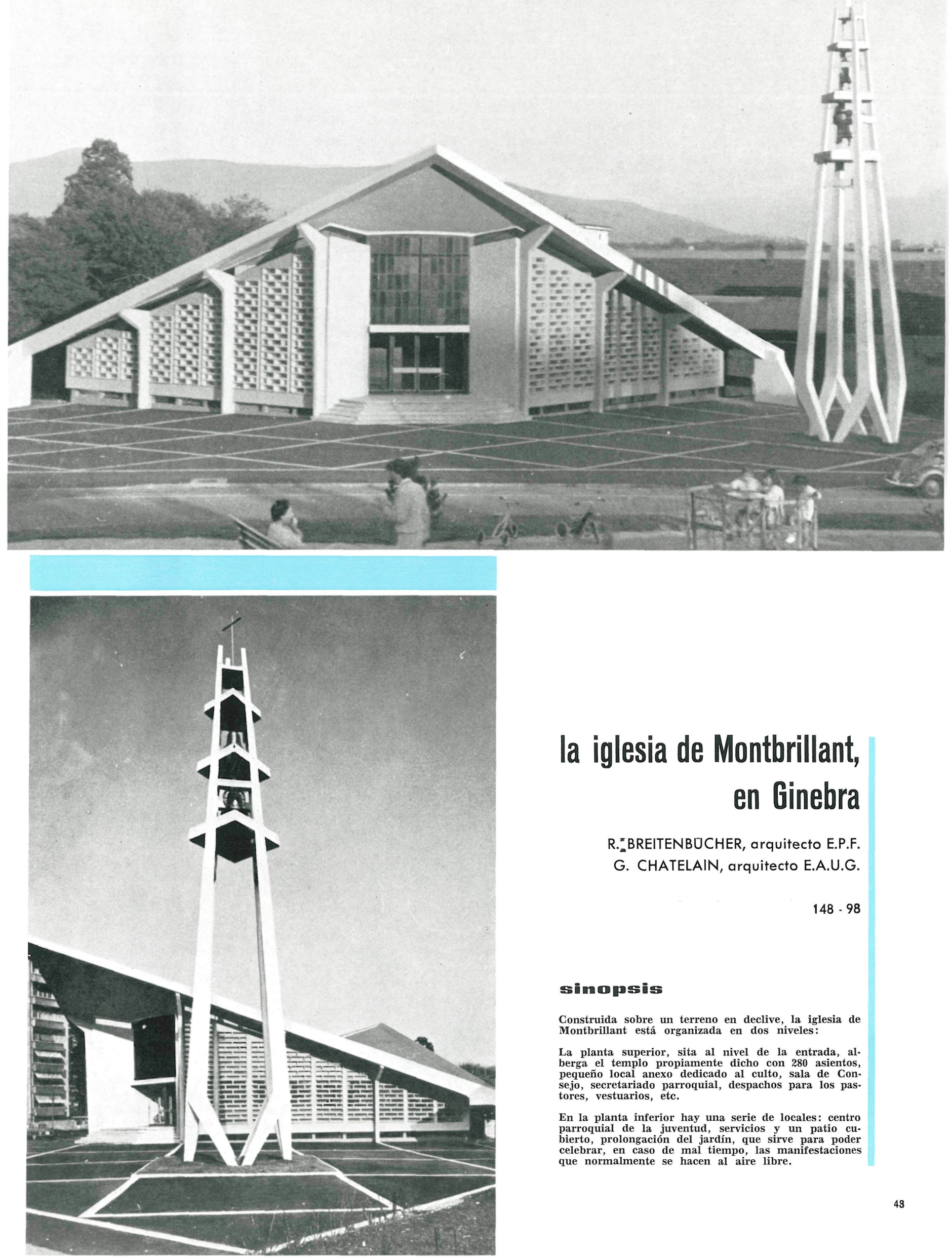

\title{
la iglesia de Montbrillant, en Ginebra
}

R.."BREITENBUCHER, arquitecto E.P.F. G. CHATELAIN, arquitecto E.A.U.G.

\section{simopsis}

Construida sobre un terreno en declive, la iglesia de Montbrillant está organizada en dos niveles:

La planta superior, sita al nivel de la entrada, alberga el templo propiamente dicho con 280 asientos, sejo, secretariado parroquial, despachos para los pastores, vestuarios, etc.

En la planta inferior hay una serie de locales: centro parroquial de la juventud, servicios y un patio cu* bierto, prolongación del jardín, que sirve para poder celebrar, en caso de mal tiempo, las manifestaciones que normalmente se hacen al aire libre. 


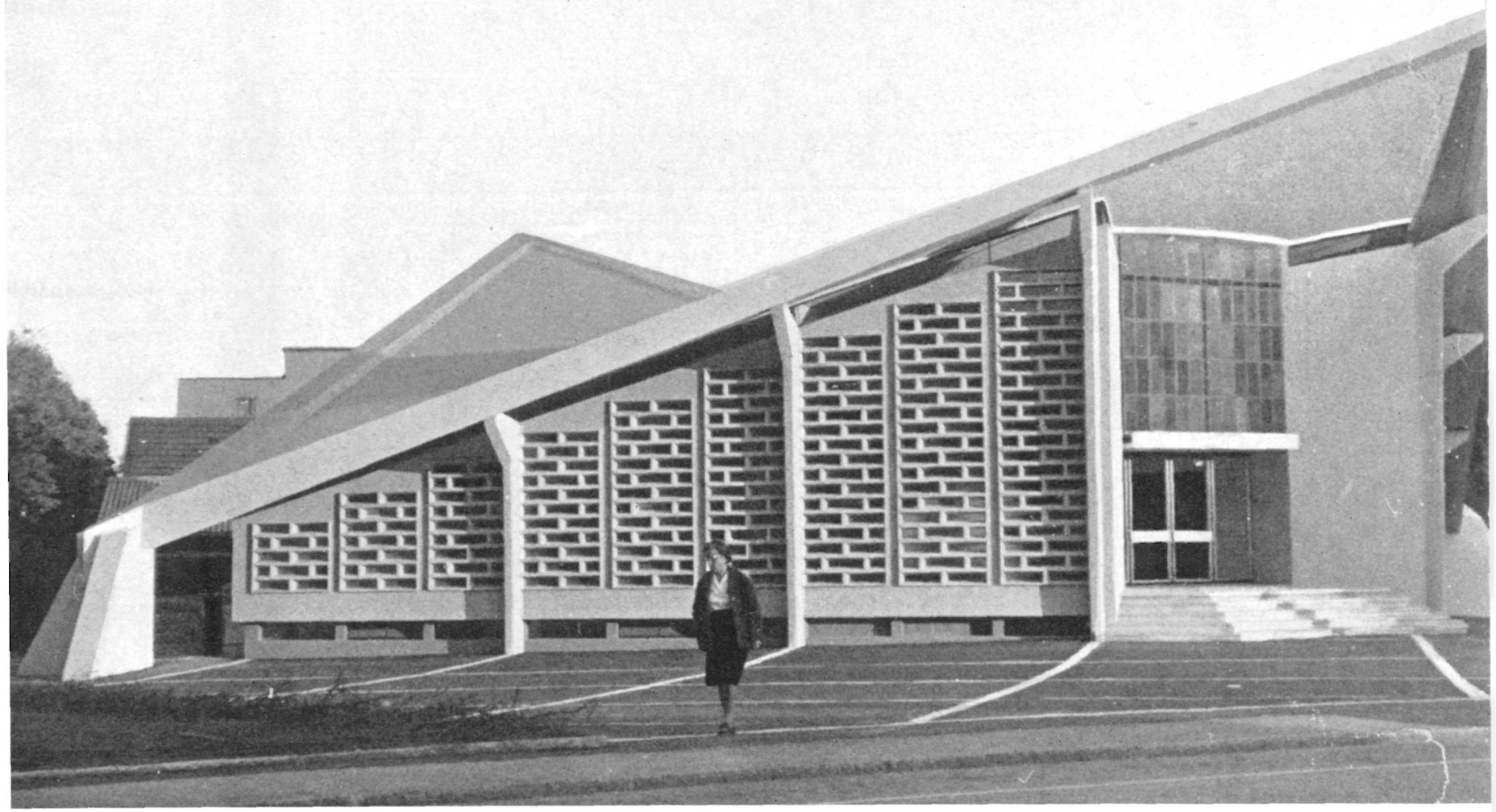

En el centro de un moderno barrio residencial de Ginebra, sobre una parcela situada al lado de la magnífica zona verde del antiguo dominio de Beaulieu y jardín de Cropettes, se alza la iglesia de Montbrillant.

Para aprovechar al máximo la pendiente natural del terreno, los arquitectos proyectaron y organizaron sus distintas dependencias en dos plantas: una al nivel de la calle, con amplia explanada de acceso, y otra, al nivel del jardín inferior.

El templo propiamente dicho con sus 280 asientos, el pequeño local anexo dedicado al culto, sala del Consejo, secretariado parroquial, despachos para los pastores, vestuarios, etc., ocupan la planta superior.

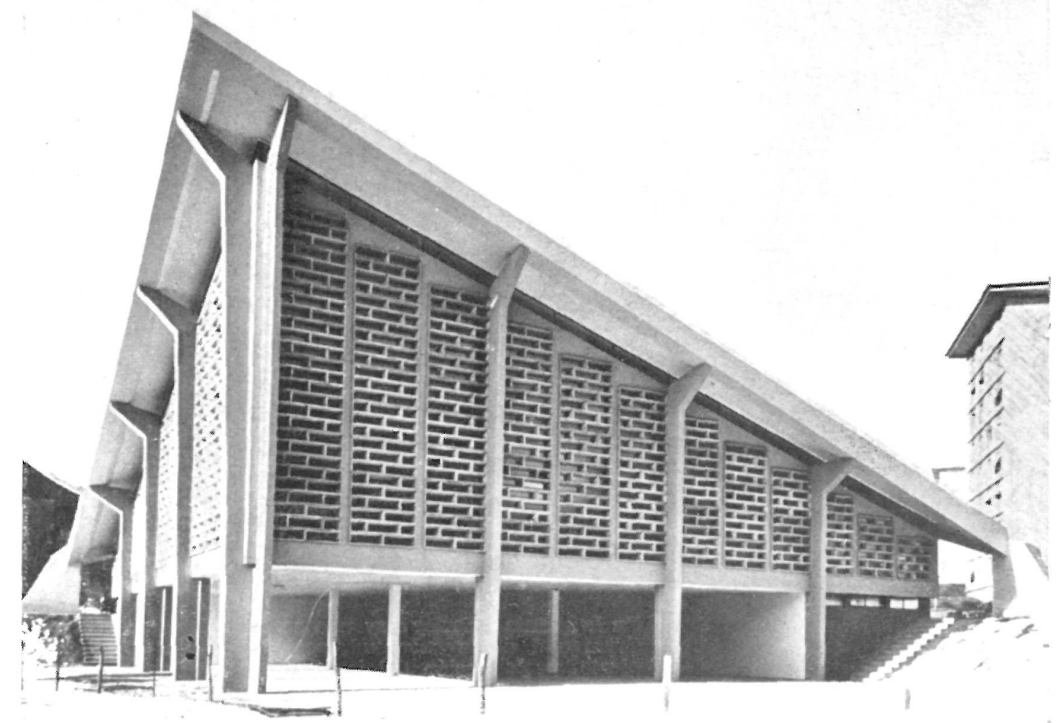

Una serie de puertas plegables permiten incorporar la pequeña sala del culto y la del Consejo-cuando es necesario-al templo, incrementando así el número de asientos hasta 450 .

La edificación adopta en planta la forma de un cuadrado, una de cuyas diagonales, la perpendicular a la calle, sirvió de eje para la composición del edificio. Esta disposición permitió distribuir los bancos para los fieles en tres sectores, convergentes - en abanico abierto a $90^{\circ}-$ hacia el ángulo en el que están agrupados los elementos principales del culto; facilitar el acceso al comulgatorio; crear un contacto más íntimo entre el predicador y los feligreses, y acentuar el sentimiento de comunidad. La forma del techo viene a reforzar ese concepto de convergencia hacia el altar. 


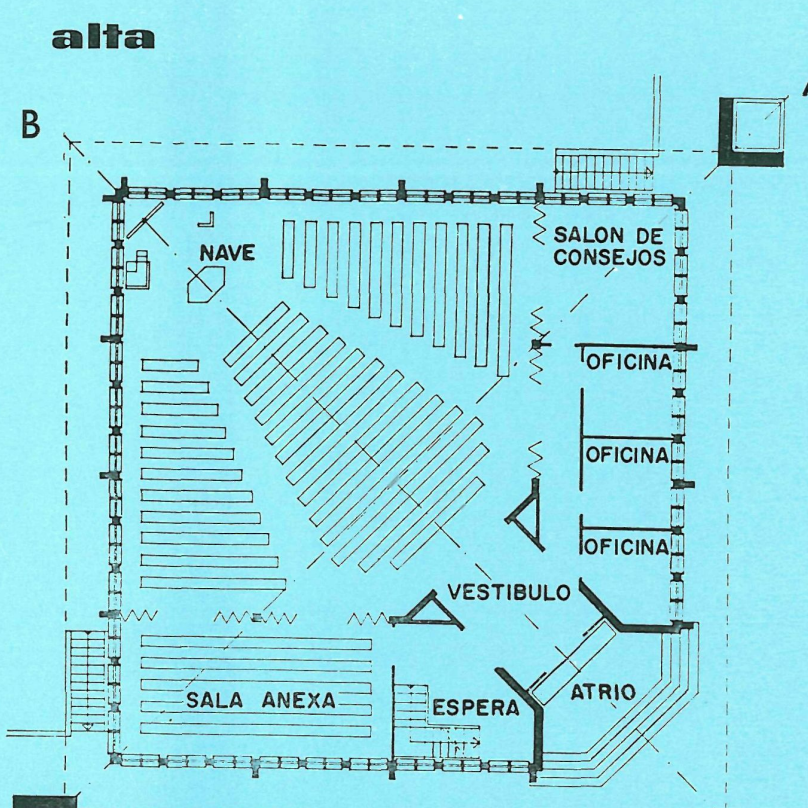

A

p Ia m m

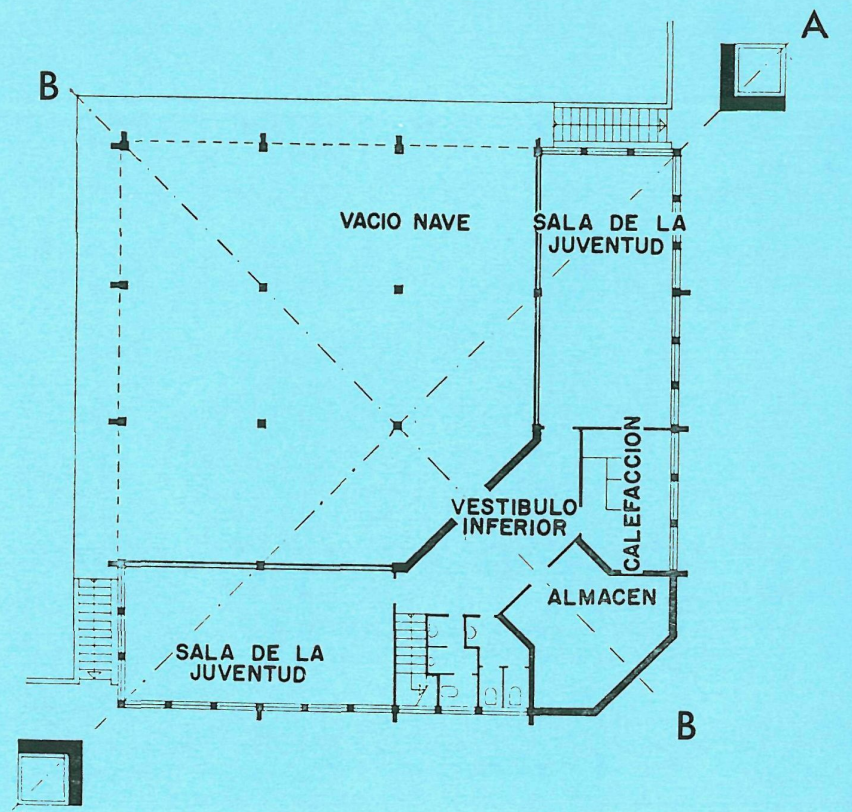

A

B

A

$2^{Q}$
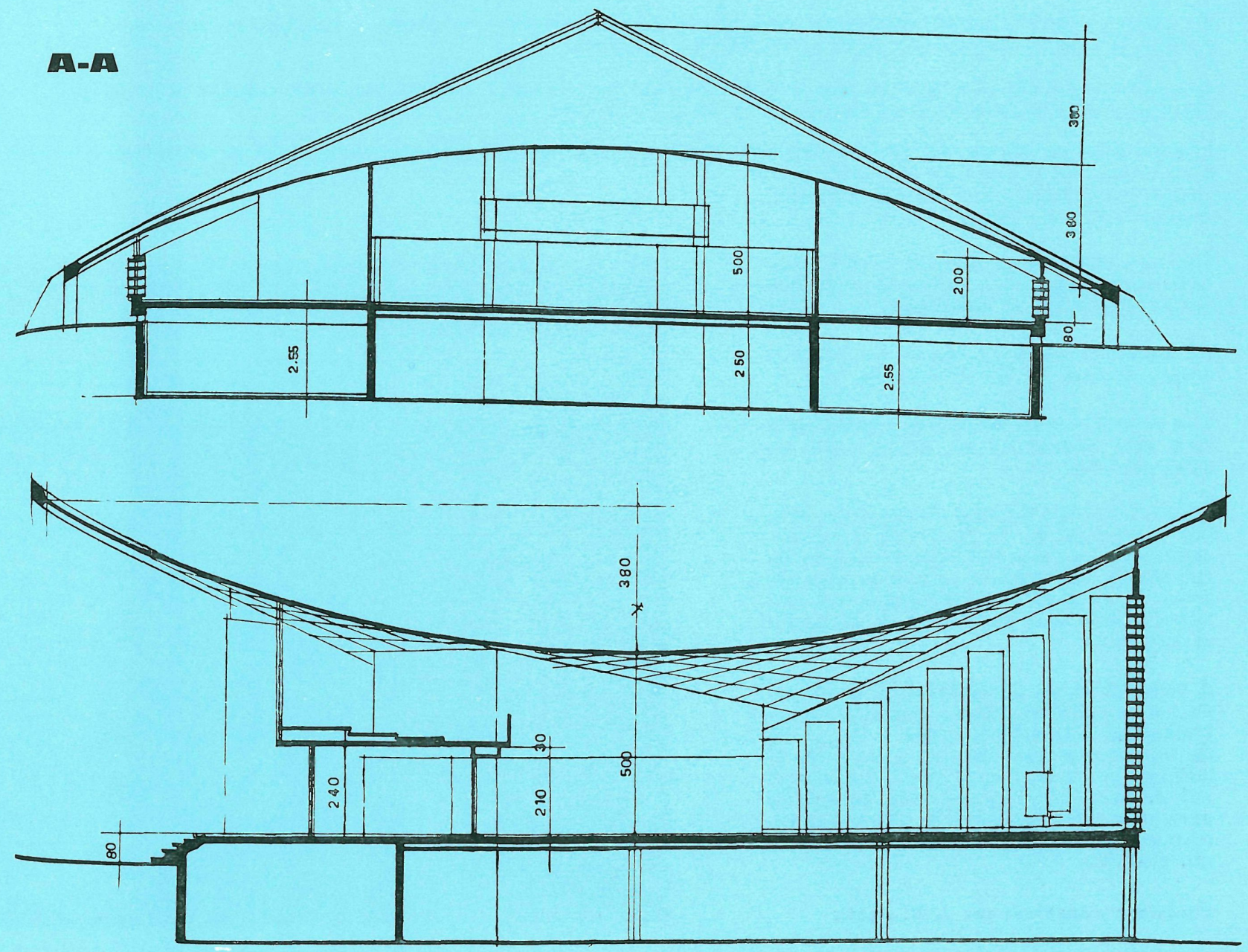

BB-B

SECEIDIES 


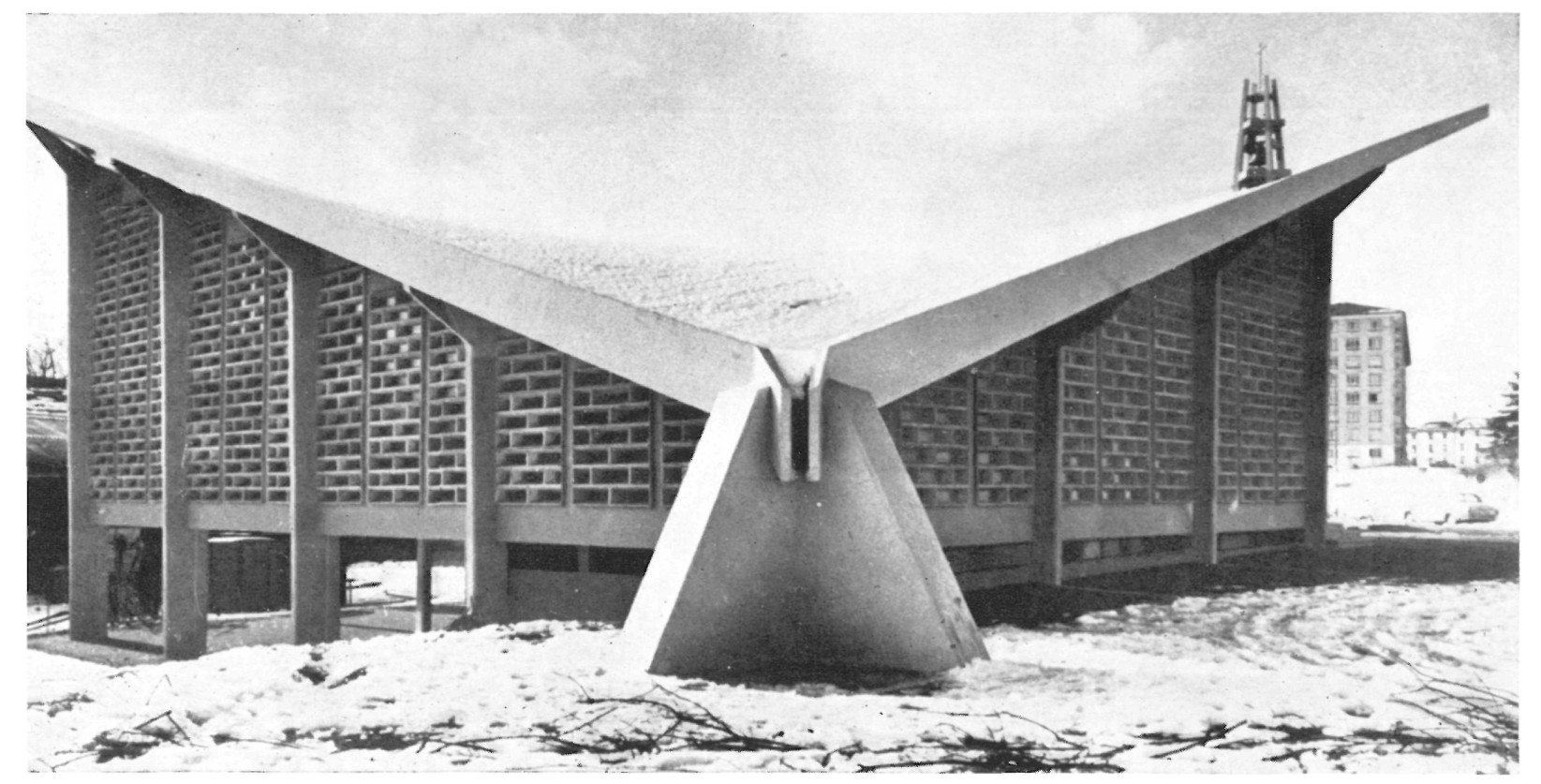

El ambiente creado en el interior del templo por esta composición en planta y volumen ha sido realizado mediante el empleo del color como energía radiante.

Los vidrios del interior, que la mayor parte de ellos son de color, forman una gran vidriera de tonalidad general azul, con algunos contrastes en rojo y amarillo.

Las paredes exteriores, en celosía, han sido construidas a base de piezas prefabricadas de hormigón, que forman una serie de alvéolos, cuya profundidad impide que los rayos solares deslumbren a los fieles.

Dichos alvéolos están cerrados con vidrios policromos que crean múltiples manchas coloreadas sobre el hormigón.

El ambiente así obtenido es luminoso y alegre, incluso en los días grises.

Los revestimientos interiores y mobiliario han sido realizados en madera, en su color natural.

El nivel inferior del edificio contiene: centro parroquial de la juventud, servicios, etcétera, y un patio cubierto, prolongación del jardín, que sirve para que puedan celebrarse, en caso de mal tiempo, las manifestaciones que normalmente se hacen al aire libre.

A unos $12 \mathrm{~m}$ de la edificación, en dirección a la calle, se alza el campanil, cons. truido en hormigón armado y de $15 \mathrm{~m}$ de altura, que goza de una gran diafanidad, y contrasta con el ritmo horizontal del edificio. El campanil está concebido para tres campanas de 200,350 y $730 \mathrm{~kg}$, respectivamente, accionadas por mecanismo eléctrico.

Traducido y adaptado por J. M. Rubio.

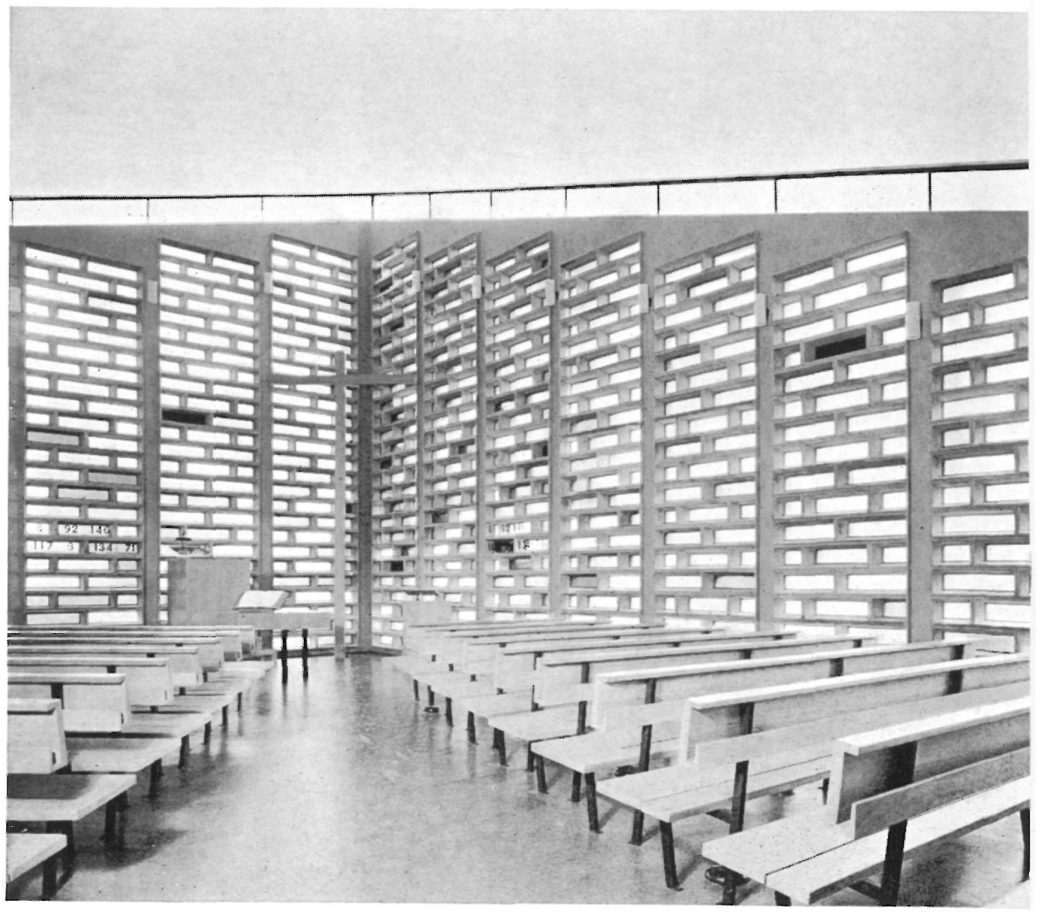




\section{L'égliśce de Montbrillant à Genève}

R. Breitenbücher, architecte E. P. F.

G. Chatelain, architecte E. A. U. G.

Construite sur un terrain en pente, cette église a été organisée sur deux plans.

Au niveau supérieur, qui est celui de l'entrée, se trouvent le temple proprement dit, de 280 places assises, la petite salle de culte annexe, la salle du Conseil, les bureaux des pasteurs, le secrétariat paroissial, les vestiaires, etc.

Au niveau inférieur se trouvent deux locaux pour la jeunesse, les toilettes et un préau couvert, qui, en cas de mauvais temps, abrite les manifestations qui, normalement, se font à l'air libre.

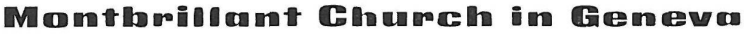

R. Breitenbücher, architect E. P. F.

G. Chatelain, architect E. A. U. G.

This church was built on sloping ground, and has two functional levels.

On the ground floor there is a church hall, with accommodation for 280 people, and a small annex with an additional chapel, a council chamber, parochial secretariat, offices and vestry.

Below there is a number of additional facilities, such as a parochial youth centre, and a covered court, which extends into the garden and serves in unsuitable weather to hold the activities that are normally practised out of doors.

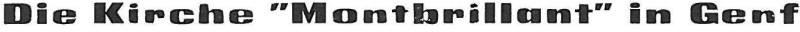

R. Breitenbücher, Architekt E. P. F.

G. Chatelain, Architekt E. A. U. G.

Die Kirche von Montbrillant steht an einem Abhang und wurde in zwei Ebenen angeordnet:

Das obere Stockwerk in Eingangsebene enthält den eigentlichen Kirchenraum mit 280 Plätzen, einen kleinen Nebenraum, einen Versammlungssaal, das Seǩkretariat der Pfarrei, Diensträume für die Pastoren und Umkleideraum, etc.

Das untere Stockwerk umfasst eine Reihe von Räumen wie: Jugendraum, Wasch- und Toilettenräume und einen überdachten Innenhof, der als Verlängerung des Gartens für Freilichtveranstaltungen bei schlechtem Wetter dient. 